\title{
AS BASES E OS DESAFIOS IMEDIATOS DA CIÊNCIA DO DIREITO EM HANS KELSEN
}

\author{
THE BASES AND THE IMMEDIATE CHALLENGES OF HANS KELSEN'S \\ SCIENCE OF LAW
}

${ }^{1}$ Mateus Di Palma Back

\section{RESUMO}

O propósito do presente paper é a apresentação de um material didático sintético expondo as bases teóricas da Teoria Pura do Direito (e não seu fundamento filosófico ou seus precursores teóricos) e os desafios teóricos que decorrem imediatamente da propositura desse desenvolvimento teórico, especialmente os relativos à especificidade lógica da norma jurídica.

Palavras-chave: Teoria pura do direito, Normativismo, Imputação, Norma fundamental

\begin{abstract}
The purpose of the present paper is the presentation of a synthetic didactic material exposing the theoretical basis of the Pure Theory of Law (and not its philosophycal foundation or its theoretical predecessors) and the challenges that imediatly follow the proposing of such theoretical development, specially those relating to the logical specificity of the legal norm.
\end{abstract}

Keywords/Palabras-claves/Mots-clés: Pure theory of law, Normativism, Imputation, Fundamental norm

1 Mestre em Direito na Universidade do Vale do Rio Sinos. Universidade do Vale do Rio Sinos - Unisinos, Rio Grande do Sul. Brasil - E-mail: mateusdpb@hotmail.com 
I.

O presente paper corresponde tem como único objetivo a apresentação didática dos fundamentos, tal como estão postos por Hans Kelsen, da Teoria Pura do Direito e dos desafios teóricos imediatos que estes mesmos acarretam. Em virtude do propósito didático da material aqui apresentado, algumas notas preliminares devem, no entanto, acompanhar esse humilde esforço. Sua pretensão deve ser clara para que não haja espaço para irresignação com certas conclusões em aberto que são deixadas ao leitores.

Primeiramente, se precisássemos esclarecer o propósito de um tal material, o que o motiva, diríamos que a razão principal deste existir é uma tradicional má compreensão da teoria kelseniana do Direito. Existem, acreditamos, razões legítimas para a crítica do trabalho de Hans Kelsen, razões que não convém que enunciemos aqui. Mas muito esforço crítico é dedicado à caricatura de um Kelsen exegeta ou um Kelsen apologista do Direito estadual - isto num momento em que trincheiras mais promissoras já foram escavadas para que o estudioso que adentra neste campo temático não fique razoavelmente frustrado com algumas (más) concepções bastante superficiais. Novamente aqui não cumpre nominarmos trabalhos particulares. Para fins de legitimação do esforço didático, o que foi dito basta.

Num segundo plano, é bom que esclareçamos que as bases do método normativo são expostas aqui somente no que toca à sua apresentação sintetizada na Teoria Pura do Direito. Muita leitura complementar é necessária para uma compreensão aprofundada da teoria kelseniana do Direito. Leitura que segue desde outros textos seus até mesmo uma compreensão razoável dos seus fundamentos kantianos. Mas esse trabalho não poderia dividir espaço com uma apresentação tão introdutória quanto o material que aqui submetemos. Aliás, essas considerações aqui expostas devem estar ao menos précompreendidas para aqueles que desejam uma critica aprofundada do método normativo.

Por fim, aos problemas imediatos que apresentamos como decorrências imediatas das postulações teóricas de Kelsen não serão ofertadas soluções nem alternativas (mesmo aquelas que o próprio Kelsen possa ter preterido). Reforços à essas ponderações bem como rechaços teóricos devem ter espaços que lhes sejam apropriados. Certamente quaisquer hipóteses de constructos teóricos alternativos aos apresentados inicialmente por Kelsen mereceria ao menos um trabalho que lhe fosse integralmente dedicado - coisa que, reiteramos, não é a proposta desse material. 
II.

O que Kelsen pretende no terceiro capítulo é justamente dar forma metodológica à "pureza" que ele se propôs alcançar desde a primeira página da Teoria Pura do Direito $^{1}$, o que significa propor uma metodologia para o estudo do Direito que não pode ser caracterizada como psicológica, historiográfica, política ou sociológica. Conhecer o Direito "puro" implica em uma ciência que seja jurídica, ou seja, que conheça juridicamente o Direito.

O ponto fundamental do terceiro capítulo, como veremos logo em seguida, é que tal estudo se dá a partir das normas jurídicas e, portanto, dizemos que a ciência jurídica em Kelsen é uma ciência normativa do Direito. Remetendo à noção de "pureza" que foi mencionada anteriormente, uma metodologia que busca abdicar de conhecer o seu objeto de qualquer maneira que não seja exclusivamente jurídica não pode ter outro objeto nem referencial que não a norma jurídica.

Por esta razão as proposições descritivas elaboradas através dessa metodologia, que buscam descrever as normas jurídicas de maneira "objetiva" e "exata", acabaram sendo denominadas proposições jurídicas. O que não quer dizer que essas proposições são normas e devam orientar a produção de novas normas de qualquer espécie, são descrições de dever ser e não prescrições de dever ser ou descrições de ser. Por isso é importante lembrar que o sentido de normatividade que a jurisprudência kelseniana carrega, como explicou Bobbio, é de normativo-descritivo, e não explicativoprescritivo (e nem normativo-prescritivo ou explicativo-descritivo), uma vez que a teoria serve para descrever as normas (que são os próprios dever ser) como elas são e não como deveriam ser e nem como vieram a ser:

Dado que as duplas "normativo-explicativo" e "prescritivo-descritivo" não se sobrepõem, não há nada de contraditório em afirmar, como faz Kelsen, que a ciência jurídica é ao mesmo tempo descritiva e normativa: descritiva no sentido de que não prescreve; normativa no sentido de que aquilo que descreve não são fatos, mas normas, é descritiva não do que existe, mas do que deve ser. Enquanto Sollsätze, as proposições que caracterizam a

\footnotetext{
1 “Quando a si própria se designa como 'pura' teoria do Direito, isto significa que ela se propõe garantir um conhecimento apenas dirigido ao Direito e excluir deste conhecimento tudo quanto não pertença ao seu objeto, tudo quanto não se possa, rigorosamente, determinar como Direito. Quer isto dizer que ela pretende liberar a ciência jurídica de todos os elementos que the são estranhos. Esse é o seu princípo metodológico fundamental.” (KELSEN, 2006, p.1)

2 No prefácio à primeira edição, o próprio Kelsen esclarece que objetivara fazer sua teoria "[...]aproximar tanto quanto possível os seus resultados do ideal de toda a ciência: objetividade e exatidão." (KELSEN, 2006, p.XI)
} 
ciência jurídica distinguem-se por um lado dos Seinsätze próprios das ciências sociais (causais), e, por outro, das Sollnormen de qualquer sistema normativo. (BOBBIO, 2006, p.58)

Quer dizer que a ciência do direito em Kelsen, até para atingir o status do que Kelsen entendia por ciência, pretende - através de proposições descritivas - não mais do que descrever o seu próprio objeto: que é o próprio Direito; mas há que se esclarecer que esse objeto a ser descrito é a própria norma jurídica e, mesmo quando isso não fica perfeitamente evidente, também o próprio ordenamento jurídico.

O emprego dessa metodologia faz com que, por exemplo, o jurista, diferentemente do sociólogo ou do economista, ao observar uma alienação de coisa entre sujeitos mediante a satisfação de certas cláusulas, não abstraia "uma relação interpessoal caracterizada por certa estrutura de poder" ou "a produção e distribuição de riqueza de certo modo característico" mas sim um contrato, ou um ilícito penal ou qualquer outra coisa desde que corresponda à certa norma jurídica (ou represente uma significação captável pelo ordenamento jurídico). Mais do que explicar a própria realidade física sob a perspectiva do Direito, é a própria norma jurídica é que é revelada pela conformação da proposição à norma jurídica (ou melhor ainda, ao ordenamento jurídico). O que o método propicia é o conhecimento da norma jurídica valendo-se da própria norma jurídica como ferramenta cognitiva.

III.

Isso nos leva, então, à construção dessa metodologia que será exposta no capítulo III. Kelsen inicia o capítulo Direito e ciência apontando que o que constitui-se como objeto de estudo da ciência jurídica, como mencionado anteriormente, é a norma jurídica ${ }^{3}$. Estudar juridicamente o Direito é estuda-lo a partir das normas jurídicas normativamente. E, apesar de esclarecer que a conduta ou as relações humanas só interessam ao direito enquanto objeto de (e constituídas por) normas jurídicas, pouco se esclarece nesse primeiro momento sobre no que se constituem essas normas jurídicas.

E não nos referimos aqui ao fato de elas pertencerem à uma determinada ordem prescritiva (dever ser). O dever ser, diria Kelsen, "um dado imediato da nossa consciência" (2006, p.6) e, apesar de ser uma categoria importante para a construção da

\footnotetext{
3 "Na afirmação evidente de que o objeto da ciência jurídica é o Direito, está contida a afirmação - menos evidente - de que são as normas jurídicas o objeto da ciência jurídica [...]” (KELSEN, 2006, p.79)
} 
teoria, não precisa ser mais explorado do que isso neste momento. Partimos da noção que sua distinção do ser é autoevidente.

Não tratamos aqui de diferenciar as normas das proposições jurídicas, o que efetivamente foi feito neste capítulo e será abordado mais adiante. No primeiro momento, Kelsen somente deixa claro que o estudo da norma jurídica, dependendo se o enfoque recai sobre as i) normas jurídicas produzidas ou ii) a produção das normas jurídicas, refere-se à uma (“i”) teoria jurídica estática ou à uma (“ii") teoria jurídica dinâmica (KELSEN, 2006, p.79-80). Também podemos dizer mais que enquanto um estudo se volta para a norma jurídica em vigor, outro se volta para o sentido de produção e, portanto, de validade da norma jurídica. E isso já suscita uma série de problemas não foram diretamente abordados nesse capítulo, mas nos quais nos deteremos nesses primeiros instantes.

\section{O reconhecimento da norma jurídica a partir da sua estrutura estática}

Para elaborar uma compreensão geral do que seria a norma jurídica sob o enfoque do princípio estático, no capítulo Estática jurídica nos deparamos de imediato com um dos conceitos mais caros à Teoria Pura do Direito: a sanção. O conceito é importantíssimo justamente porque caracteriza a única distinção formal entre as normas jurídicas e as normas morais que, ainda que se admita que essas também produzam uma coação psíquica $^{4}$, são carentes do emprego de força física socialmente organizada:

O Direito só pode ser distinguido essencialmente da Moral quando - como já mostramos - se concebe como uma ordem de coação, isto é, como uma ordem normativa que procura obter uma determinada conduta humana ligando à conduta oposta um ato de coerção socialmente organizado, enquanto a Moral é uma ordem social que não estatui quaisquer sanções desse tipo, visto que as suas sanções apenas consistem na aprovação da conduta conforme as normas e na desaprovação da conduta contrária às normas, nela não entrando sequer em linha de conta, portanto, o emprego da força física. (KELSEN, 2006, p.70) 
Bobbio explicaria noutra oportunidade que enquanto as normas morais caracterizam-se pela sanção interior ${ }^{5}$, justamente porque são decorrentes de um sentimento do indivíduo, as normas jurídicas se caracterizam por uma sanção exterior e institucionalizada ${ }^{6}$, uma vez decorrem não de um sentimento pessoal de remorso, mas de vontade de outras pessoas organizada institucionalmente. Poderíamos suspeitar da atitude de despir a sanção moral de qualquer conformação social e resguardá-la somente como um sentimento de remorso, mas não podemos negar que, em virtude da presença da possibilidade de violência física socialmente organizada (institucionalizada), a sanção seria, por excelência, o elemento estrutural da norma que a caracterizaria como jurídica.

No entanto, Kelsen, que tanto depende de que esse artefato teórico preceda ou proceda $^{7}$ da norma para a sua caracterização, não pareceu poder conhecer a sanção jurídica exceto como a coerção psíquica decorrente da possibilidade do emprego da força física institucional, ou, de maneira geral, da possibilidade institucionalizada de realização de um $\mathrm{mal}^{8}$. Isso se torna um problema pois a maneira como se propõe a estudar o direito normativamente extrapola as dimensões normativas do direito, como teria observado Warat:

\footnotetext{
4 KELSEN, 2006, p.38.

5 "Há um modo de definir as normas morais que se refere precisamente à sanção. Afirma-se que são morais aquelas normas cuja sanção é puramente interior. Por sanção, entende-se sempre uma consequência desagradável da violação, cujo fim é prevenir a violação ou, no caso em que a violação seja verificada, eliminar as consequências nocivas. A única consequência desagradável da violação de uma norma moral seria o sentimento de culpa, um estado de incômodo, de perturbação, às vezes de angústia, que se diz, na linguagem da ética, 'remorso' ou 'arrependimento'.” (BOBBIO, 2014, p.154155)

6 "Temos tendência a fazer coincidir a juridicidade com a organização e a organização com a institucionalização da sanção. Por isso, julgamos poder dizer que a sanção externa e institucionalizada é uma característica distintiva das normas jurídicas." (BOBBIO, 2014, p.160)

7 Ver em KELSEN, 2006, p.44-46, mas também mais adiante, quando Kelsen retoma que tanto na pena quanto na execução, “[a]mbas as espécies de sanções consistem na realização compulsória de um mal $[\ldots]^{\prime \prime} \cdot(2006$, p.122)

“[...]um mal que é aplicado ao destinatário mesmo contra a sua vontade, se necessário empregando até a força física coativamente, portanto." (KELSEN, 2006, p.35).
} 
Verificou-se que o normativismo kelseniano caracteriza a sanção como a privação devida de certos bens: vida, saúde, liberdade, etc., feita por um órgão da comunidade; assim, a sanção é vista como um ato de coerção devido. Mas, a definição de coerção que Kelsen oferece é extranormativa. É fruto de um estudo comparativo de todos os ordenamentos jurídicos existentes ou que tenham existido. Assim, o conceito de coerção devida surge de um estudo empírico e não estrutural; surge a partir de uma análise por meio da qual se define a estrutura lógica das normas e proposições jurídicas e se indica um dos elementos materiais das ordens jurídicas. Como se pode, portanto, construir uma teoria pretensamente rigorosa a partir de um elemento tão pouco delimitado? Por certo, a definição de sanção, em Kelsen, é circular. (WARAT, 1983, p.95)

Quanto a essa observação, o próprio Luís Alberto Warat parece corrigir a "impureza" do conceito, deslocando-a de uma base material/substantiva do conceito para uma outra que é formal/normativa, ao apontar que ainda podemos "definir a sanção como a conduta prevista no consequente da norma" (1983, p.96), e veremos mais adiante como a teoria kelseniana suportaria esses argumentos. No entanto, ao abandonarmos esse conceito kelseniano de sanção, que parece se apoiar mais em dados psicológicos (coerção psíquica) ou sociológicos (possibilidade institucional de: violência física, privação de liberdade, realização de um mal) do que normativos, perdemos momentaneamente o elemento estrutural que qualificava a norma jurídica como sendo jurídica, propriamente falando.

Lembrando que mesmo que, para Kelsen, as sanções das normas morais não sejam mais do que uma atitude de aprovação ou reprovação da conduta humana enquanto estando em acordo ou desacordo com a norma moral ${ }^{9}$, é de se preocupar: será que elas não deixam de ser ainda condutas previstas como consequentes das normas (cabendo dentro do conceito "repurificado", normativo, de sanção)? Mas o que diferenciaria a sanção moral da sanção jurídica não seria justamente a possibilidade do emprego socialmente organizado da força física que antes fomos obrigados a abandonar para manter a coerência normativa e a "pureza" na proposta metodológica de Kelsen?

\footnotetext{
${ }^{9}$ KELSEN, 2006, p.71.
} 
Não é o objetivo desse trabalho responder a estas perguntas. Ainda assim, sem que possamos identificar a juridicidade da norma jurídica - que se daria em função da sanção - não temos normas através das quais conhecer conceitos como dever jurídico ou relação jurídica, de que se ocupa o estudo da estática jurídica.

Precisamos saber então, normativamente e para além de qualquer equívoco, o que torna a norma jurídica uma norma jurídica. Para isso, Kelsen foi muito mais contundente com o estudo da dinâmica jurídica que, apesar do desenvolvimento e nível de abstração, também não deixou de suscitar certas discussões sobre questões possivelmente obscurecidas no encerramento hermético do Direito sob a redoma do normativismo.

Mais uma vez teremos de investigar o próprio desenvolvimento da ciência normativa para entender o que garante a sua normatividade; dessa vez, através do princípio dinâmico (também introduzido no capítulo ora trabalhado). E, por hora, isso significa abordar sucintamente a questão da norma fundamental.

O reconhecimento da norma jurídica a partir da estrutura dinâmica do ordenamento jurídico

Diferentemente da teoria jurídica estática, que estuda o Direito em seu momento estático, como ele se apresenta, a teoria jurídica dinâmica se propõe a estudar o direito em seu processo de produção e aplicação - essa aplicação do Direito, aliás, realizada pelos magistrados e por órgãos executivos, também é produção do Direito, como veremos mais adiante. Tudo isso, ainda que de maneira extremamente sucinta, foi dito também no capítulo Direito e ciência ${ }^{10}$. No entanto, tal como à teoria jurídica estática, a atenção despendida à teoria jurídica dinâmica foi meramente introdutória.

${ }^{10}$ KELSEN, 2006, p.80. 
E, embora o desenvolvimento da teoria dinâmica tenha sido reservado à um outro capítulo, existe uma razão importante para nos determos brevemente nesses estudos: a teoria dinâmica se dedica, mais do que a teoria estática poderia, a desvelar o sentido de validade da norma jurídica através do seu processo de produção. E a validade de uma norma jurídica não é outra coisa que não sua juridicidade. $O$ que a caracteriza objetivamente como norma jurídica. E, como já observamos em alguns pontos anteriormente, para uma ciência que busca estudar o Direito a partir das normas jurídicas - seu elemento constitutivo - delimitar normativamente o que são as normas jurídicas é um problema que deva se impor metodologicamente.

Ainda que aceitássemos sem as resistências anteriormente apresentadas a caracterização das normas jurídicas através da sanção como elemento estrutural, e lidando com sanção enquanto ameaça da imputação institucional de um mal, um outro problema razoável que Kelsen se propõe é o de diferenciar as normas jurídicas do mero emprego de ameaça sob a possibilidade de emprego da força física. Lidando com o tradicional exemplo da quadrilha de salteadores, como poderíamos diferenciar de um lado a ameaça acompanhada do comando de um salteador, e do outro a sanção jurídica? Como poderíamos diferenciar, no âmbito da validade da norma jurídica, uma execução judicial de um delito criminal?

Mais do que simplesmente responder a essas perguntas, Kelsen teve o desafio de propor uma metodologia que realizasse o reconhecimento da norma jurídica normativamente. Quer dizer que não se está permitido recorrer à uma explicação de matriz política, sociológica ou psicológica para se diferenciar a norma jurídica do comando do salteador.

Segundo a proposta normativista de Hans Kelsen, o que fundamenta a validade de uma norma jurídica posta é justamente outra norma jurídica posta. Dizemos isso num sentido de que uma norma jurídica confere sentido de comando a outra norma jurídica, não interessando o conteúdo da norma jurídica em questão. O que quer dizer que quando um juiz aplica uma sentença, o que confere validade jurídica a norma individual criada no caso é uma outra norma jurídica, dessa vez geral - ou, antes disso, um conjunto de normas jurídicas que a precedem nessa regressão de conferir poder. Não é um irreparável equívoco propor que a norma é válida porque foi posta em virtude de uma série de circunstâncias que a validam (juiz competente, legalidade da norma, registro e publicação, etc.), mas mesmo essas circunstâncias são assentadas normativamente (por 
exemplo: o juiz é competente porque existe uma norma que fixa a sua competência). $\mathrm{O}$ que só faz esclarecer que a validade da norma individual é decorrente de uma estrutura normativa que lhe confere esse sentido (juridicamente objetivo) de comando. Estrutura normativa aqui referida como uma ou mais normas jurídicas que lhe precedem genealogicamente e numa estrutura coerente e hierárquica.

Então existe uma ordem jurídica escalonada onde as normas postas recolhem sentido de normas postas imediatamente superiores a elas que, por sua vez, recolhem sentido de normas postas que lhes sejam imediatamente superiores e assim sucessivamente num percurso - ou, para valermos da linguagem do livro, processo que segue desde o nível mínimo desse ordenamento escalonado, que corresponderia às normas individuais (sentenças, atos administrativos, etc.), até as normas postas de nível máximo que seriam, no modelo kelseniano, as normas constitucionais. Mas o que garante o sentido de validade das normas postas constitucionais?

Não podemos admitir que essa regressão que se faz para verificar o sentido de validade se realiza ad infinitum por ao menos duas boas razões: nunca se responderia de forma conclusiva o que confere normativamente o sentido de validade da norma jurídica e rapidamente se esgota a possibilidade de verificar empiricamente a postura das normas jurídicas (leis, decisões paradigmáticas, doutrinas e costumes). As normas precisam ser verificáveis (portanto postas) para que se possa descrevê-las em conteúdo através de proposições descritivas dessa ciência do Direito.

Para resolver o problema do limite dessa regressão, Kelsen valeu-se da pressuposição de uma norma jurídica sem conteúdo cuja única finalidade é conferirsentido de comando - e ser a ferramenta cognitiva de todas as outras ferramentas cognitivas - às normas postas superiores: a norma fundamental gnosiológica. Aliás, por ser uma norma pressuposta e não posta, ela não tem como ser verificada, sendo, portanto, hipotética. Deve-se entender que a norma fundamental é um artifício teórico que garante a normatividade do Direito da mesma maneira que os conceitos puros do entendimento (as categorias da lógica transcendental) permitem o entendimento daquilo apresentado pela apercepção pura segundo a epistemologia kantiana - e isso não é mais do que dizer garantir que o conhecimento seja algo formado exclusivamente no sujeito. 
Ainda assim, há que se tomar cuidado para que a pressuposição da norma fundamental não seja tomada por arbitrária, ela surge da necessidade de fundamentação racional do o processo silogístico ${ }^{11}$ através do qual a validez de uma norma jurídica é considerada válida, ou seja, como uma necessidade racional em que uma premissa maior é pressuposta. E ela cumpre bem o seu papel de impedir que perguntas como "quem instituiu o poder instituinte" provoquem a necessidade de uma permanente e complexa investigação político-sociológica para a identificação de cada norma discutida ser jurídica ou não (e em último grau, se o direito é jurídico ou não). A norma fundamental presta unidade e identidade ao ordenamento jurídico nos permitindo identificar, finalmente, as normas jurídicas, e por isso Kelsen afirma, segundo a lógica do princípio dinâmico ${ }^{12}$, que:

Todas as normas cuja validade pode ser reconduzida a uma mesma norma fundamental formam um sistema de normas, uma ordem normativa. A norma fundamental é a fonte comum da validade de todas as normas pertencentes a uma e mesma ordem normativa, o seu fundamento de validade comum. $\mathrm{O}$ fato de uma norma pertencer a uma determinada ordem normativa baseia-se em que o seu último fundamento de validade é a norma fundamental desta ordem. É a norma fundamental que constitui a unidade de uma pluralidade de normas enquanto representa o fundamento da validade de todas as normas pertencentes a essa ordem normativa. (KELSEN, 2006, p.217)

\footnotetext{
11 Nos referimos ao silogismo por meio do qual se identifica a validade de qualquer norma integrante do ordenamento jurídico. Observemos: "A fundamentação da validade de uma norma positiva (isto é, estabelecida através de um ato de vontade) que prescreve uma determinada conduta realiza-se através de um processo silogístico. Neste silogismo a premissa maior é uma norma considerada como objetivamente válida (melhor, a afirmação de uma tal norma), por força da qual devemos obedecer aos comandos de uma determinada pessoa, quer dizer, nos devemos conduzir de harmonia com o sentido subjetivo destes atos de comando; a premissa menor é a afirmação do fato de que essa pessoa ordenou que nos devemos conduzir de determinada maneira. A norma cuja validade é afirmada na premissa maior legitima, assim, o sentido subjetivo do ato de comando, cuja existência é afirmada na premissa menor, como seu sentido objetivo." (KELSEN, 2006, p. 226) Até mesmo pode-se perceber como a norma constitucional - norma posta de mais alto grau - é tida como objetivamente válida, sua existência (validez) afirma uma norma superior que a preceda e lhe atribua sentido de comando; como, no entanto, essa norma não pode ser verificada, ela é tida como pressuposta.

12 "O princípio segundo o qual se opera a fundamentação da validade das normas deste sistema é um princípio dinâmico.” (KELSEN, 2006, p.219)
} 
Então, finalmente resolvemos como distinguir as normas jurídicas daquele comando sob ameaça de violência física do salteador. Enquanto a norma jurídica poderá ser rastreada verificando na ordem escalonada de normas o seu sentido de comando até a norma fundamental gnosiológica pressuposta, o comando do salteador não o poderá. É de se questionar se tanto basta para saber se a norma integra o ordenamento jurídico, sendo então direito ou não. Quer dizer, se o exercício lógico que nos levou a pressuposição da norma fundamental gnosiológica não pode ser repetido com uma ordem jurídica estranha, como a dos salteadores, gerando um conflito não entre as normas - ou seja, uma aparente antinomia jurídica -, mas entre ordenamentos jurídicos (se reconhecendo mutuamente como válidos ou não)?

Kelsen parecia suspeitar da questão ele próprio pois fez depender (parcialmente) a validade do ordenamento jurídico de uma espécie de eficácia geral e duradoura que ganhou pouco destaque na elaboração de sua teoria do direito - e nenhuma menção, por motivos evidentes, no capítulo apresentado onde ele começa a desenvolver a sua metodologia normativa. Quer dizer, não se poderia se abdicar da abstração uma vez que tanto depende dela. O sentido de comando somente, sentido subjetivo, não serve para caracterizar uma norma jurídica (que não deixa, no entanto, de estar devidamente provida com tal qualidade), ela só pode ser efetivamente reconhecida pela regressão à norma fundamental. Entretanto, quando Kelsen se propõe honestamente essa questão de porque não presumir uma norma fundamental validando a ordem do bando de salteadores, ele resolve:

Mas - e é esta a questão decisiva - por que é que não se pressupõe essa norma fundamental? Ela não é pressuposta porque, ou melhor, se esse ordenamento não tem aquela eficácia duradoura sem a qual não é pressuposta qualquer norma fundamental que se lhe refira e fundamente a sua validade objetiva. (KELSEN, 2006, p.53)

Aqui somos confrontados com um problema que parece aproximar perigosamente o positivismo jurídico kelseniano com as escolas realistas do Direito ${ }^{13}$ (a exceção de que é o próprio ordenamento que tem sua validade dependendo da eficácia,

\footnotetext{
13 Entendemos aqui, por realismo jurídico, a tendência teórica de se reduzir a validade da norma jurídica à sua eficácia. Tal abordagem foi bem exposta em BOBBIO, 2014, p.56, 63-70.
} 
o que permite ainda que tenhamos normas válidas porém sem eficácia). A impressão é possibilitada pela aparente confusão entre critérios (valor, validade, eficácia) que, segundo pensadores como Bobbio (e mais obviamente Kelsen com sua noção de pureza), idealmente deveriam manter-se absolutamente independentes ${ }^{14}$.

Diferentemente de Hans Kelsen, Norberto Bobbio ${ }^{15}$, que esta altura não consegue deixar de se perguntar se "a norma fundamental não acaba sendo uma solução fictícia", não encontra problemas em admitir que "é necessário reconhecer que aquilo que fecha o sistema não é a norma, mas o poder" (2006, p.165 e 166). Tal conclusão não segue somente no sentido de reconhecer o chamado sentido subjetivo que é o ato primeiro de comando, o poder soberano que corresponde à norma fundamental. Diz mesmo o que Kelsen não o deixou perfeitamente claro com o recurso à eficácia geral: que ao dizer que a ordem jurídica na qual se presume a grundnorm possui mais eficácia que uma organização de bandidos, se diz que ela tem mais poder e é isso que fornece validade para o Direito (enquanto se reconhece esse único Direito). Mas se podemos dizer tanto, podemos prescindir totalmente da norma fundamental que deixa de ter função:

A norma fundamental teria tido sua função se tivesse conseguido evitar o obstáculo de toda teoria positivista do direito, que é a derivação do direito de fato. Mas uma teoria como a kelseniana, que resolve a validade de um ordenamento jurídico em sua efetividade, não resolve esse obstáculo, mas dele se utiliza para encontrar um sólido ponto de chegada. A teoria normativa do direito é a reiteração histórica mais convincente que, uma vez descartada a solução jusnaturalista, segundo a qual é direito aquilo que é justo, não existe outra solução além daquela segundo a qual é direito aquilo que é de fato comumente observado (que é a velha tese de Austin): Ex facto oritur ius. Em suma, a norma fundamental teria a função de transformar o poder em direito. (BOBBIO, 2006, p.166)

A conclusão de Bobbio seria que a norma fundamental seria uma maneira normativa de substituir a fórmula jusnaturalista lex facit regem que justifica o estado de

\footnotetext{
${ }_{15}^{14}$ BOBBIO, 2014, p.50.

15 Que percebeu em Kelsen muito bem assentado o recuso à eficácia da ordem jurídica: “[...] a essa altura, o critério para distinguir o comando jurídico do comando não jurídico é outro. Não é mais a pertença ao ordenamento cuja validade repousa na norma fundamental, mas é a própria validade do sistema. Conhecemos bem a solução que Kelsen deu a este quebracabeça: um ordenamento jurídico é válido só se for também eficaz, ou seja, se as normas que ele produz são, em linhas gerais (im grossen und ganzen), observadas. Aquilo que falta à quadrilha de bandidos, dado que os seus atos sejam habitualmente golpeados pelo ordenamento estatal como ilícitos, é a efetividade.” (BOBBIO, 2006, p.164)
} 
Direito. E nos lembramos aqui que é justamente com um recurso a teoria dinâmica do direito que Kelsen abre capítulo Direito e Estado (no qual ele se dedica a desconstruir essa "ideológica" dualidade). Mas se mais uma vez a verificação da validade da norma jurídica depende de elementos extra-normativos (que não estão rigorosamente vinculados à validade da norma), no caso a eficácia geral do ordenamento jurídico, dessa vez ainda temos um referencial de validade da norma jurídica através do qual podemos conformar o método da ciência normativa do Direito.

As implicações negativas dessa "impureza" teórica não necessitam ser exploradas neste trabalho. Temos, apesar dos percalços, o que viemos procurar - e o que estava insuficientemente apresentado ao principiar do capítulo III da Teoria Pura do Direito: a norma jurídica posta.

IV.

Se todo esse trabalho foi em decorrência de que o reconhecimento da norma jurídica antecede a sua descrição e portanto integra a metodologia que se pretendeu elaborar no capítulo estudado, o que efetivamente não pôde ser postergado na própria elaboração do capítulo foi a distinção dessas normas jurídicas - o dever ser objeto da ciência jurídica - das proposições científicas que pretendem descrevê-las, que são as anteriormente mencionadas proposições jurídicas - que descrevem o ser daquele dever ser objetivamente verificável através das reflexões apresentadas no item anterior. Quer dizer, se o dever ser, que é o próprio sentido de comando, denota o sentido subjetivo de uma norma jurídica, uma vez pertença ela a determinada ordem jurídica, ela deixa de estar vinculada somente ao sentido de comando e torna-se um dado objetivo, posto no mundo do ser e imediatamente verificável enquanto norma.

As proposições jurídicas, então:

[...] são juízos hipotéticos que enunciam ou traduzem que, de conformidade com o sentido de uma ordem jurídica nacional ou internacional - dada ao conhecimento jurídico, sob certas condições ou pressupostos fixados por esse ordenamento, devem intervir certas consequências pelo mesmo ordenamento determinadas. (KELSEN, 2006, p.80)

Ao passo que as normas jurídicas:

[...] não são juízos, isto é, enunciados sobre um objeto dado ao conhecimento. Elas são antes, de acordo com o seu objeto, mandamentos e, como tais, comandos, 
imperativos. (KELSEN, 2006, p.81)E, embora as duas se apresentem sempre através de enunciados verbais, o que realmente interessa é o seu sentido e não o seu conteúdo. As instituições normativas podem pôr a mesma norma jurídica através de diversas enunciações diferentes como a ciência jurídica poderá descrevê-la da mesma forma. A verificabilidade das proposições jurídicas não está adstrito à mera comparação de identidade verbal entre certos enunciados.

O que realmente importa é que o sentido mandamental das normas jurídicas, efetivamente, constitui o Direito. E, dado que podemos verificar as normas como integrantes de um ordenamento (o jurídico) ou não, nos interessa saber se são válidas ou inválidas. E, por outro lado, as proposições jurídicas, que tem sentido descritivo, por essa razão mesma, não estão sujeitas a esse mesmo critério de avaliação. Nos interessa saber se elas descrevem adequadamente o sentido prescritivo das normas jurídicas, podendo estarem corretas ou não, sendo verdadeiras ou falsas ${ }^{16}$.

Note-se que esses critérios de avaliação são decorrentes justamente das diferentes ordens lógicas que as proposições descritivas e normativas estão inseridas (ordem do ser e do dever ser) ${ }^{17}$. Não se pode dizer que uma proposição jurídica é válida ou inválida da mesma maneira que não se pode dizer que uma norma jurídica seja verdadeira ou falsa. E por isso enquanto as normas jurídicas se ocupam de constituir o Direito, as proposições se ocupam, mais ou menos acertadamente, em ensiná-lo.

\footnotetext{
16 Aqui Kelsen incorre em um problema que ele não pôde efetivamente resolver mais adiante no capítulo sobre interpretação quando ele reconhece duas ordens de indeterminações semânticas que suspeitosamente constituem a moldura interpretativa. "Pode-se afirmar que a verdade das proposições jurídicas, em função da correspondência de dois sentidos, é uma tese semiologicamente problemática, pois carrega a ilusão de que o sentido das normas é unívoco. Além disso, estar-se-ia esquecendo que os

efeitos do reconhecimento do sentido de uma norma depende de representações costumeiras, da ideologia e de um complexo jogo de correlações de força no seio das instituições, que devem ser vistas como emissores institucionais dos sentidos jurídicos." (WARAT, 1983, p.75) Na verdade, podemos dizer que a metodologia proposta nesse capítulo não serve para dizer como o Direito será - ou seja, o teor das leis e mesmo das decisões por vir dos juízes. Se a Teoria Pura dissesse como o juiz deve decidir ou como o legislador deve legislar, ela seria uma teoria prescritiva do Direito, e não descritiva. Mas como então descrever o Direito como ele é prescindindo de orientar a interpretação ou descrever variáveis isoladas psicológicas ou sociológicas da decisão? A afirmação de Warat é justa. A pureza se omite.

17 As proposições e as normas, das quais nos são relevantes as jurídicas, aparecem no curso Teoria da

Norma Jurídica de Norberto Bobbio respectivamente como proposições descritivas e normativas. Assim, também é exemplar a forma que ele explica a diferença nos seus critérios de valoração: "O critério com que valoramos as primeiras para aceitalas ou rejeitá-las é a correspondência com os fatos (critério de verificação empírica), ou com os postulados autoevidentes (critério de verificação racional), segundo se trate de proposições sintéticas ou analíticas. Chamamos de empiricamente verdadeiras as proposições cujo significado é verificado por via empírica, e racionalmente verdadeiras as que são verificadas por via racional. O critério com que valoramos as segundas para aceita-las ou rejeitá-las é a correspondência com os valores últimos (critério de justificação material) ou a derivação das fontes primárias de produção normativa (critério de justificação formal). Chamamos de justas (ou convenientes) as primeiras, de válidas, as segundas.” (2014, p.83) Daí fica fácil perceber que enquanto as proposições jurídicas dependem de verificação racional, as normas jurídicas dependem de justificação formal.
} 
Se segundo a epistemologia kantiana que influenciou a teoria pura, como sugere Kelsen $^{18}$, o conhecimento contribui para a produção do objeto, essa produção, segundo o próprio, “tem um puro caráter teorético ou gnosiológico. Ela é algo completamente diferente da produção de objetos pelo trabalho humano ou da produção do Direito pela autoridade jurídica" (2006, p.82). E isso condiz com o idealismo ${ }^{19}$ da epistemologia kantiana. Podemos dizer que o conhecimento do Direito afeta - ou ao menos pode afetar - de fato a produção do Direito, mas não que ele produza (juridicamente) Direito.

E nesse mesmo sentido, ainda que se possa dizer que o legislador ou o juiz precisem conhecer o Direito para produzir as normas jurídicas, o conhecimento do Direito não é essencial ${ }^{20}$ como é, por exemplo, a investidura na função competente para realizar essa produção (investidura em competência que, como mencionamos, se opera normativamente). A norma jurídica, objetivamente verificável, é posta por um ato de comando que constitui o seu sentido subjetivo; não é revelada, ensinada ou expressada, é ordenada.

Para entender melhor essa dinâmica, mencionamos já no item II deste trabalho que, ainda que diferenciemos formalmente as leis da sentença e do ato administrativo, a aplicação da norma jurídica não é outra coisa que a própria produção da norma jurídica. Kelsen admite, lá no seu oitavo capítulo da Reine Rechtslehre que o Direito, ao ser aplicado, é interpretado pelo aplicador. A norma jurídica é apresentada através de um enunciado e portanto qualquer um com capacidade de compreendê-lo pode interpretá-la. Mas a metodologia que começa a ser formulada neste capítulo terceiro nos ensina que a interpretação legítima - que é aquela que vale para a norma - é a aquela que põe a norma e não aquela que a esclarece. Isso porque a interpretação legítima não é a interpretação verdadeira do sentido normativo, é a interpretação válida.

V.

Adiante, no que afinal implica a diferença metodológica entre a ciência normativa do Direito e outras ciências que estudam o fenômeno jurídico como, por exemplo, a sociologia do Direito? Para Kelsen, essa diferença numa distinção de

\footnotetext{
18 KELSEN, 2006, p.82.

19 Tratamos, grosseiramente, por idealismo a concepção de que a realidade - no caso, o mundo fenomênico - não passa de uma conjunção de ideias, sensações ou, no caso de Immanuel Kant, intuições organizadas de certa maneira.

20 KELSEN, 2006, p.81.
} 
princípios lógicos que conectam os fatos numa ordenação de eventos estudados pelas ciências. Tratamos aqui do princípio da causalidade e do princípio da imputação.

Para Kelsen, a natureza é uma "ordem das coisas ou um sistema de elementos que estão ligados uns com os outros como causa e efeito, ou seja, portanto, segundo um princípio que designamos por causalidade" (2006, p.84). As ciências naturais estudam a conexão entre fatos (estes denotados idealisticamente como elementos) numa relação lógica de ser, de inescapável procedência, a qual seria denotada na lei natural. Se a lei natural indutivamente abstraída explica a conexão entre os fatos de maneira adequada, podemos dizer que ela está correta (sendo, como distinguimos antes, verdadeira) ${ }^{21}$, caso não explique, dizemos que está incorreta (sendo falsa). Segundo Kelsen, as ciências encarregadas de estudar essa ordem das coisas logicamente ligadas segundo o princípio da causalidade seriam as ciências da natureza. O Direito, apesar de ser uma ordem normativa, também está inserido no mundo da natureza ${ }^{22}$ e por isso pode ser estudado por essas ciências naturais.

No entanto, a sociedade, diferentemente da natureza "é uma ordem normativa de conduta humana" (KELSEN, 2006, p.85) onde os fatos estão relacionados não como causa e efeito mas como pressuposto normativo e consequência; transgressão e castigo ou adequação e recompensa, como veremos. Então, de maneira análoga ao sistema natural de elementos, temos que:

O objeto das ciências sociais - a sociedade - é para Kelsen, um sistema de elementos ligados segundo um princípio diferente daquele da causalidade: 0 da imputação. Este princípio, também, une dois elementos externados mediante um enunciado condicional, mas sem lhes atribuir uma relação de causa e efeito, senão interpretando-os conforme um critério de retribuição castigo ou recompensa - de forma que o primeiro elemento do enunciado condicional, seja visto como uma transgressão ou adequação. (WARAT, 1983, p.68)

\footnotetext{
${ }^{21}$ E aqui não convém explicar que, da maneira como se resolve os fatos científicos hodiernamente, esse juízo de adequação seja somente uma ideia bastante crível assegurada (deduzida) pelos fatos observados

devidamente catalogados ou reproduzidos em experimentos que isolam variáveis para denotar a confiabilidade (verificabilidade) de certa abstração, sendo portanto uma verdade relativa e útil e não eterna e certeira. Em outras palavras, as ciências buscam formas de explicar as coisas e não verdades.

22 Temos que ter cuidado aqui. O Direito está inserido na natureza exclusivamente enquanto um fato social. A Teoria Pura do Direito é, antes de qualquer outra coisa, uma teoria que nega as chamadas fontes naturais ou transcendentais do Direito (a vontade de deus, a razão humana, etc.) e tenta fundar o Direito única e exclusivamente nele mesmo. Kelsen não nega que a sociedade esteja inserida no mundo da natureza, mas reconhece uma diferença na conexão entre nos fatos da natureza e nos fatos sociais.
} 
Lembremos que o Direito é, para a ciência normativa, uma ordem normativa e portanto um fato social por excelência e, ainda que, como já afirmamos anteriormente, se possa estudá-lo como causa ou consequência de algo, ele é objeto típico de uma espécie de ciência orientada pelo princípio da imputação: a ciência social. Por essa lógica, as ciências sociais seriam sempre ciências normativas pois a sociedade é, segundo o princípio da imputação, uma ordem normativa ${ }^{23}$. Em resumo o que diferencia as ciências sociais das ciências naturais é justamente segundo se estuda uma conexão entre fatos segundo, respectivamente, os princípios da imputação ou da causalidade ${ }^{24}$.

Desta concepção de ciência, temos diversos exemplos facilmente identificáveis de ciências naturais: física, química, biologia, oceanografia e uma infinidade de outras que partem do mesmo princípio e método. Ocorre que, dada esta classificação que Kelsen procede em adotar sobre quais são as ciências naturais e sociais, ciências como sociologia, etnologia, psicologia e história, historicamente entendidas como ciências sociais, por estudarem de maneira geral o comportamento humano, também passam a integrar o já extenso rol de ciências naturais. Isso porque estudam seus respectivos objetos, que podem abranger até mesmo a moral, o direito e a religião, por meio do princípio da causalidade.

Levando em conta o que foi dito sobre as ciências sociais serem ciências normativas e sobre a identificação das ciências em virtude dos princípios os quais orientam suas investigações, Kelsen explica que essas ciências que estudam o comportamento humano em função do princípio da causalidade podem ser entendidas como ciências sociais causais. Ao passo que as ciências que se ocupam de estudar o comportamento humano em função do princípio da imputação - sendo, portanto, ciências sociais em sentido estrito - podem ser entendidas como ciências sociais

\footnotetext{
23 "Chegamos, desta forma, a um ponto importante: a sociedade, como objeto das ciências sociais, é regida, para Kelsen, pelo princípio da imputação e, por isto, é sempre um conjunto de enunciados normativos” (WARAT, 1983, p.68).

24 Interessante apontar aqui que muitos sociólogos partiram de distinções semelhantes para aludir conclusões bastante distintas. A socióloga e professora da UFSC Ilse Scherer-Warren definiu o social

como "um conjunto de relações comandadas por uma dialética de opressão e libertação" (em Movimentos Sociais); o sociólogo Zygmunt Bauman já traduziu provocativamente a sociedade numa segunda natureza que, da sua própria maneira, desafia à vontade humana (em Por uma sociologia crítica); e similarmente o psicólogo social Serge Moscovici mencionou a coerção social do dever imposto pelo grupo como elemento comum ao vínculos sociais. A sanção, o castigo, a coerção, a opressão, o poder, os limites são todas figuras que se correspondem e, em certo sentido, evocam imputação e, de maneira velada, a norma social. É de se supor que tais categorias persistirão recorrentes até que se revele com mais precisão do que constitui o social da sociedade; uma boa indicação, a que foi usada pelo sociólogo Niklas Luhmann, é a comunicação.
} 
normativas. Essas últimas seriam a Ética, que estuda a moral, a Jurisprudência, que estuda o direito e a Teologia, que estuda as normas religiosas.

Todas teriam a função de explicar o comportamento humano através de enunciados descritivos e leis, mas algumas diferenças fundamentais sobre esses enunciados e leis emergem e justamente em decorrência das diferenças entre os princípios da imputação e da causalidade. Tais diferenças são duas apenas e de ordem lógica e isso reflete sobremaneira na atividade descritiva do jurista.

Primeiramente, os juízos hipotéticos nos quais se apresentam as proposições jurídicas, ao relacionar os fatos segundo uma imputação (um valor, um comando, uma autorização, etc.), não necessitam que a consequência prevista siga do pressuposto fixado para que seja a descrição acertada. De fato, pode-se muito bem seguir-se o contrário do que foi estipulado como consequência sem que isso signifique a imprecisão da descrição. Isso porque numa relação causal quando se percebe ocorrer um evento dado como causa, um outro evento dado como consequência decorre do primeiro (se A é, B é), enquanto numa relação normativa o que se afirma não é que uma consequência seja, mas que deva ser (se A é, B deve ser). Essa diferença de ordem lógica é percebida nas formas verbais usadas nos diferentes enunciados descritivos, ser em proposições causais e dever ser em proposições normativas. Em resumo: no princípio da imputação, na ocorrência que algo seja não segue necessariamente que algo seja, mas que algo deve ser; no princípio da causalidade, dado que algo seja, é seguido que outro algo seja.

A segunda diferença entre a causalidade e a imputação é que os fatos relacionados como causa e efeito sempre são precedidos de outras causas e procedidos de outros efeitos numa cadeia causal interminável. É difícil se conceber uma causa primeira sem que se recorra a fórmulas metafísicas como a vontade criadora de Deus ou a vontade livre do homem. E mais difícil ainda conceber um fato final onde toda eventualidade termina. Nos fatos relacionados pelo princípio da imputação, no entanto, a cadeia de pressupostos e consequências é finita. Um pressuposto normativo que estabelece um pecado, por exemplo, embora tenha uma razão causal de ser, não precisa necessariamente ser precedido de uma imputação anterior, tal como sua consequência, digamos uma penitência, não precisa produzir necessariamente um novo fato normativo.

Mas o que isso significa para as leis jurídicas? Significa que, apesar das leis jurídicas procederem de maneira análoga às leis naturais, a analogia cessa em um ponto essencial. Antes de explica-lo, contudo, devemos esclarecer que quando tratamos de lei 
jurídica, não estamos tratando de normas jurídicas, ainda que certas normas geraiscarreguem a denominação de "leis". E isso quer dizer essencialmente distinguir as atividades do cientista do Direito, que é a de conhecer o Direito, da atividade dos operadores e instituições do Direito, que é a de produzi-lo.

Assim como a lei natural é uma afirmação ou enunciado descritivo da natureza, e não o objeto a descrever, assim também a lei jurídica é um enunciado ou afirmação descritiva do Direito, a saber, a proposição jurídica formulada pela ciência do Direito, e não o objeto a descrever, isto é, o Direito, a norma jurídica. (KELSEN, 2006, p.90)

As leis naturais se baseiam observações passadas, fatos que se seguiram que aparentemente se relacionavam, para elaborar uma descrição mais ou menos acertada da realidade. Os enunciados descritivos das ciências causais se referem aos eventos passados mas se voltam para o futuro. Quer dizer, mesmo uma ciência causal do comportamento humano, como a sociologia, só explica o que ocorreu no passado enquanto tentando entender o que vai ou pode acontecer no futuro. Nós nos servimos das leis naturais como uma maneira de prever o futuro.

As leis jurídicas que descrevem as normas jurídicas não podem ser utilizadas com o mesmo propósito. Quando enunciamos descritivamente que o metal dilata ao ser aquecido, nos é certo que, ao aquecermos o metal, ele dilatará. Quando enunciamos descritivamente que o indivíduo que comete um homicídio deve ser sofre pena de reclusão e uma grande rejeição social, não decorre necessariamente que ele sofra a pena de reclusão e nem rejeição social de qualquer tipo. Isso porque não estamos descrevendo uma conduta ou outra em especial com tais enunciados, estamos descrevendo normas jurídicas.

As normas jurídicas não são, como já se salientou, afirmações, quer sobre acontecimentos futuros, quer sobre acontecimentos passados. Em regra, elas referem-se, na verdade, a uma conduta humana futura. Porém, nada afirmam sobre essa conduta, mas prescrevem-na, autorizam-na ou permitem-na. (KELSEN, 2006, p.98)

E quando se descreve que algo deva acontecer, é justamente no sentido descrever uma prescrição, autorização ou permissão. Não, como a forma verbal em português também possa sugerir, que é provável que tal aconteça.

Se, ao modo do que Kelsen acusa de "jurisprudência realística", uma ciência tivesse a pretensão de explicar o conteúdo das normas ainda por serem postas, ou seja, 
prever como se daria a decisão do juiz ou propostas das câmaras legislativas ou asordens dos órgãos executivos, tal previsão se daria completamente prejudicada por um referencial, a norma jurídica, que pouco ou nada determina sobre essas questões.

Mais do que isso, a própria metodologia que está aqui sendo construída estaria arruinada pois tal conhecimento é referente a ordem causal da realidade social e não normativa propriamente dizendo (ainda que seja sobre normas jurídicas). Quer dizer, na produção da norma jurídica concorrem fatores de ordens sociológica, psicológica, ideológica (etc.), enquanto no reconhecimento da validade da norma jurídica somente a ordem normativa seria determinante.

\section{BIBLIOGRAFIA BASE}

KELSEN, Hans. Teoria pura do direito. São Paulo: Martins Fontes, 2006.

BOBBIO, Norberto. Direito e Poder. São Paulo: Editora Unesp, 2006.

BOBBIO, Norberto. Teoria da Norma Jurídica. São Paulo: Edipro, 2014.

WARAT, Luis Alberto. A pureza do poder. Florianópolis: Editora da UFSC,1983. 